\title{
(C) OPEN ACCESS \\ Extended opening hours and patient experience of general practice in England: multilevel regression analysis of a national patient survey
}

- Additional material is published online only. To view please visit the journal online (http://dx.doi.org/10.1136/ bmjqs-2016-005233).

'Department of Primary Care and Public Health, Imperial College London, London, UK ${ }^{2}$ Centre for Health Policy, Imperial College London, London, UK

\section{Correspondence to} Thomas E Cowling, Department of Primary Care and Public Health, Imperial College London, Reynolds Building, St Dunstan's Road, London W6 8RP, UK; t.cowling@imperial.ac.uk

Received 10 January 2016 Revised 24 May 2016 Accepted 30 May 2016 Published Online First 24 June 2016

\section{SLinked}

- http://dx.doi.org/10.1136/ bmjqs-2016-005415

CrossMark

To cite: Cowling TE, Harris M, Majeed A. BMJ Qual Saf 2017;26:360-371.

\begin{abstract}
Background The UK government plans to extend the opening hours of general practices in England. The 'extended hours access scheme' pays practices for providing appointments outside core times (08:00 to 18.30, Monday to Friday) for at least 30 min per 1000 registered patients each week.

Objective To determine the association between extended hours access scheme participation and patient experience.

Methods Retrospective analysis of a national cross-sectional survey completed by questionnaire (General Practice Patient Survey 2013-2014);

903357 survey respondents aged $\geq 18$ years old and registered to 8005 general practices formed the study population. Outcome measures were satisfaction with opening hours, experience of making an appointment and overall experience (on five-level interval scales from 0 to 100). Mean differences between scheme participation groups were estimated using multilevel random-effects regression, propensity score matching and instrumental variable analysis.
\end{abstract}

Results Most patients were very (37.2\%) or fairly satisfied $(42.7 \%)$ with the opening hours of their general practices; results were similar for experience of making an appointment and overall experience. Most general practices participated in the extended hours access scheme (73.9\%).

Mean differences in outcome measures between scheme participants and non-participants were positive but small across estimation methods (mean differences $\leq 1.79$ ). For example, scheme participation was associated with a $1.25(95 \% \mathrm{Cl}$ 0.96 to 1.55 ) increase in satisfaction with opening hours using multilevel regression; this association was slightly greater when patients could not take time off work to see a general practitioner $(2.08,95 \% \mathrm{Cl} 1.53$ to 2.63$)$. Conclusions Participation in the extended hours access scheme has a limited association with three patient experience measures. This questions expected impacts of current plans to extend opening hours on patient experience.

\section{INTRODUCTION}

'The public now expect a seven day NHS', asserted the UK health secretary in parliament on 15 September $2015 .^{1} \mathrm{He}$ was explaining government policy for all general practices in England's National Health Service (NHS) to offer routine doctor appointments 7 days a week, from 08:00 to 20:00, by 2020 (table $1 \mathrm{a}$ ). ${ }^{2}$ The prime minister first announced this commitment ahead of the 2015 UK general election and restated it in his first major speech after being re-elected. ${ }^{3} 4$ Policy rhetoric focuses on 'hard working taxpayers and families' and 'appointments that fit in with their family and work life'. ${ }^{5-7}$ The government planned for 18 million patients (33\% of the population) from 2500 general practices to benefit by March 2016, with national implementation to follow. ${ }^{8}$ This is part of a wider drive to improve weekend services across the NHS, including in hospitals, and is particularly relevant to people who cannot take time off work. ${ }^{4}$ New appointments can be given by telephone or online and provided collectively between practices working in groups. ${ }^{8}$ Most practices currently offer appointments between 08:00 and 18:30, Monday to Friday only. ${ }^{9}$ The Royal College of General Practitioners opposes the plans (table 2). ${ }^{10}$

Other countries are also trying to improve access to primary care outside of current working hours. Australia recently reintroduced a national funding scheme for after-hours care where practices are 
Table 1 National policies to extend the opening hours of general practices in England

(a) Prime minister's GP access fund

What is the policy? (b) Extended hours access scheme

Payment for general practices providing appointments outside of times included in contracts (08:00 to 18:30, Monday to Friday for most practices). Practices must provide at least 30 min of additional appointments per 1000 registered patients weekly. Appointments can be with any health professional and must be in addition to normal provision during contracted hours. Sessions can be provided concurrently, for at least 30 min. Participating practices earn $£ 1.90$ per registered patient per year.

2008; revised for 2014-2015 (to allow practices to offer telephone and online appointments and work in groups to meet requirements).

5877 (of 7959; 74\%) in 2014-2015.

Unknown.

Mixed evidence from relevant evaluations in Greater Manchester and London; low demand in some areas.

effect?

£175 million investment so far (£50 million first wave; £125 million second wave). paid more for directly providing services outside of 08:00 to $18: 00$ on weekdays. ${ }^{11}$ An Italian law passed in 2013 intended for practices to work in groups to provide care 24 hours a day, 7 days a week, as part of a wide reorganisation of primary care. ${ }^{12}$ Standards for the 'patient-centred medical home' promoted as the basis for primary care reform in the USA include extended opening hours in the evenings and at weekends. ${ }^{13}$

General practices in England have been paid for extended opening hours under a dedicated scheme since 2008 (table 1b). The 'extended hours access scheme' pays practices for providing at least $30 \mathrm{~min}$ of additional appointments per 1000 registered patients each week outside of the times specified in their main contracts. ${ }^{14}$ Practices earn $£ 1.90$ (\$2.89; €2.69) per registered patient per year for meeting this requirement. ${ }^{15}$ A practice with the mean number of registered patients $\left(7426^{16}\right)$ receives $£ 14109$ for providing at least 3 hours and $45 \mathrm{~min}$ of extended opening hours per week. The total payment nationally was $£ 84$ million in 2014-2015, with 74\% (5877/ 7959) of practices participating. ${ }^{17}$ This investment is similar to that outlined for 7-day opening of general practices, for which a $£ 400$ million commitment over the five years to 2020 has been made (table 1). ${ }^{3}$

Practices participating in the scheme are advised to set their opening hours using results from the General Practice Patient Survey-an annual national study of adults registered with a general practitioner (GP). ${ }^{18} 19$ Overall experience and experience of making appointments as reported in the survey are monitored nationally as part of the NHS outcomes framework. ${ }^{20}$ Questionnaires also ask about patient satisfaction with opening hours. This provides the opportunity to examine the association of the extended hours access

Table 2 Department of Health's rationale for 7-day general practice services and the concerns of the Royal College of General Practitioners

Department of Health ${ }^{1} 27$

- This is about responding to the fact that the public now do expect a seven day NHS

- The role and purpose of seven day primary care is about much more than convenience- it is about making sure precious hospital capacity is kept clear for those who really need it

- This is a manifesto commitment that this government made, so we have to honour that, but it's part of a much bigger strategy which is a massive increase in the capacity of general practice

- We live in a 24/7 society, and we need GPs to find new ways of working so they can offer appointments at times that suit hard-working people

Text is directly quoted from the given references.

GP, general practitioner; NHS, National Health Service.
Royal College of General Practitioners ${ }^{10}$

- Evidence that seven day access is being called for by patients, or that it provides an effective use of NHS resources is, at best, mixed

- It is unrealistic to talk about extending routine services at the current time because general practice is hugely overstretched and under-resourced

- The promise of seven day access to routine GP care has further damaged morale and is likely to discourage many medical graduates from choosing general practice

- We are concerned that the proposal to provide seven day GP access to routine care could jeopardise continuity of care 
scheme with several patient experience measures that national policies presume will be affected by extended opening hours, particularly for people unable to take time off work. No studies have previously determined this association. The impact of opening 7 days a week is also largely unknown.

We examined whether patients registered to general practices participating in the extended hours access scheme report a better patient experience across three measures from the General Practice Patient Surveysatisfaction with opening hours, experience of making an appointment and overall experience. We also examined whether the associations varied by patient ability to take time off work to see a GP.

\section{METHODS}

\section{Patient experience}

The General Practice Patient Survey 2013-2014 (July to September 2013 and January to March 2014) included all general practices in England with eligible patients $(\mathrm{n}=8017){ }^{21}$ Adults with a valid NHS number and registered to a general practice for at least six months were eligible to participate in the survey. Postal questionnaires were sent to stratified (by age group, gender and practice) random samples of eligible patients in each practice, with 903357 responses for 8005 practices (34.3\% of 2631209 questionnaires sent). The mean number of 113 responses per practice (SD 18.5) provides most measures of patient experience with practice-level reliability that is 'very good' $(\geq 0.85)$ or 'excellent' $(\geq 0.90) .{ }^{22}$ The weighted respondent sample, accounting for survey design and non-response (by variables including age, gender, socio-economic status, general practice and region of England), is nationally representative. ${ }^{21}$

We analysed three patient experience domainssatisfaction with opening hours, experience of making an appointment and overall experience. Each domain was assessed using a single survey question with five response options. Satisfaction with opening hours was recorded as very dissatisfied, fairly dissatisfied, neither satisfied nor dissatisfied, fairly satisfied or very satisfied. Experience of making an appointment and overall experience were recorded as very poor, fairly poor, neither good nor poor, fairly good or very good. We treated these responses, like in previous research, as lying on an interval scale: 0 (least favourable), 25, 50, 75,100 (most favourable). ${ }^{23-25}$ All respondents were asked to complete the questions analysed. The three domains address opening hours specifically and patient experience as monitored by UK government. ${ }^{20}$

\section{Extended opening hours}

Payments made to each general practice under the extended hours access scheme 2013-2014 were obtained from the Health and Social Care Information Centre. ${ }^{26}$ Practice-level data on general practice payments became available for the first time in February
2015 and are not provided for financial years (April to March) before 2013-2014. Payments are extracted from general practice computer systems and validated against statements for each quarter of the financial year. ${ }^{26}$ Data on the extended hours access scheme were available for $99.7 \%(7981 / 8005)$ of practices in the General Practice Patient Survey data.

We considered practices that received a payment under the scheme to be scheme participants. All other practices were classed as non-participants, thus creating a binary variable. We could not measure the number of extended opening hours provided over the minimum requirement ( $30 \mathrm{~min}$ per 1000 registered patients) as payments are based solely on the number of patients registered to each practice (multiplied by $£ 1.90$ ).

Participating practices provide appointments outside of the core hours given in their main contracts. Standard core hours are from 08:00 to 18:30, Monday to Friday, for the $95 \%$ of practices with General or Personal Medical Services contracts. ${ }^{27-29}$ We excluded the remaining practices as they often open for longer as part of their main contracts, ${ }^{30}$ so not participating in the scheme does not indicate shorter opening hours for them.

\section{Patient and practice characteristics}

We analysed 12 variables as potential confounders. These variables were the main predictors of patient experience in the precursor of the General Practice Patient Survey. ${ }^{31}$

Patient characteristics were age (eight ordinal categories); gender; ethnicity (white, mixed, Asian, black, other ${ }^{32}$ ); ability to take time off work to see a GP (no, yes, not working); and confidence in managing health (four ordinal categories), as reported in the survey. Socio-economic status was measured in fifths of the national Index of Multiple Deprivation rank for the small areas in which patients lived (lower layer super output areas; mean population of 1500). ${ }^{33}$

Practice characteristics were numbers of registered patients and full-time-equivalent GPs; ${ }^{34}$ national Index of Multiple Deprivation rank for the registered population; ${ }^{35}$ urban/rural location (defined as urban if area population exceeded $10000^{36}$ ); and region of England (of 10 strategic health regions). Clinical quality was assessed using 13 intermediate outcome measures from the UK Quality and Outcomes Framework 2013$2014 ;^{37}$ these measures have the largest associations with patient experience of all framework indicators. ${ }^{38}$ We calculated the sum of achievement on the 13 measures, weighted by the relative number of points available. $^{38} 39$

\section{Statistical methods}

All statistical analysis was conducted using Stata MP V.13. We report descriptive statistics for all respondents both unweighted and weighted for survey design and non-response. ${ }^{21}$ We omitted 114 general 
practices (6809 respondents) that opened or closed within the year, had $<1000$ registered patients or $<50$ survey responses (to omit practices with atypical populations). ${ }^{40}$ The number of responses and practices eligible for inclusion for the methods outlined below were 854206 responses $(95 \%$ of original sample) and 7428 practices (93\% of original sample). When estimating associations, we excluded respondents with missing data for any of the variables in the model (12-15\% across experience measures); previous analysis of the General Practice Patient Survey found no difference in results between complete case and multiple imputation approaches. ${ }^{41}$

We estimated the association of participation in the extended hours access scheme with the patient experience measures using three approaches: multilevel random-effects regression, propensity score matching and instrumental variable analysis. These methods are robust under different assumptions, as explained in detail elsewhere. ${ }^{42}$ In each approach, estimates were adjusted for the 12 patient and practice characteristics given above. We adjusted SEs for heteroscedasticity and clustering within practices.

\section{Random-effects regression}

We first estimated multilevel linear regression models with a random intercept at the general practice level. We tested whether each patient experience measure was significantly different in practices that participated in the scheme versus practices that did not. We also tested whether any differences varied by respondent ability to take time off work to see a GP and by region of England using interactions. Policy to extend opening hours has focused on working people and national implementation. ${ }^{6}$

The random-effects regression models assume that all characteristics of patients and practices that are associated with both scheme participation and patient experience were observed and adjusted for in the models. If this assumption is false, the estimated coefficients will be biased by residual confounding. Some other biases potentially affecting the regression estimates, from misspecification of the form of the outcome equation for example, can be resolved by matching methods. ${ }^{42}$ We therefore used propensity score matching to assess the sensitivity of the results.

Propensity score matching

We used logistic regression to estimate the probability that a respondent's general practice participated in the scheme (the propensity score) based on the 12 patient and practice characteristics given above. Each respondent whose practice did participate was then compared with 100 other respondents with the most similar propensity scores whose practices did not participate (nearest neighbours matching with replacement) ${ }^{43}$ matching with 100 respondents rather than the one most similar respondent improved the balance of variables between the participant and non-participant groups. We excluded respondents with no suitable match (due to non-overlapping propensity scores). We used standardised mean differences in patient and practice characteristics between participation groups, before and after matching, to assess matching quality.

The above approaches assume that all variables associated with scheme participation and patient experience are observed and can therefore be accounted for in the models. However, it is plausible that participating practices provide other additional services that we do not have data on but that also affect patient experience, causing estimates to be biased. Instrumental variable analysis can resolve this issue if a valid instrument can be found.

Instrumental variable analysis

Valid instruments would influence scheme participation, have no effect on patient experience except through its influence on scheme participation and be unrelated to unobserved confounders. ${ }^{44}$ We considered fifths of the percentage of practices participating in the scheme in each Clinical Commissioning Group (CCG) to be a valid instrument. Such 'preference-based' geographic instrumental variables are commonly used. ${ }^{44} 45$

CCGs are groups of general practices (38 on average across 211 CCGs) that plan and commission local health services in England. The percentage of practices that participate in the extended hours access scheme varies considerably across CCGs (10th centile $=45 \%$, 90th centile $=96 \%$ ), reflecting different 'preferences' of CCGs as largely autonomous organisations. CCGs have a legitimate role in directly influencing member practices on issues such as access, while GPs often feel that their views are not reflected in CCG decisions. ${ }^{46}$ It is plausible that CCGs with similar local populations and practices can have very different views on the extended hours access scheme. This may be due to large variation in governance arrangements of CCGs, their levels of engagement with member practices and who 'owns' decisionmaking. ${ }^{46}$ We examined the association between scheme participation rates within CCGs and practice characteristics to help evaluate instrument validity.

We used two-stage least squares to estimate the effect of the scheme. We report partial $\mathrm{R}^{2}$ and $\mathrm{F}$ statistics from the first-stage regressions to assess instrument strength. Assuming that the instrumental variable does not modify the effect of scheme participation, the average effect of the scheme on scheme participants is estimated (as for the other two approaches).

\section{RESULTS}

Table 3 describes the 903357 respondents to the General Practice Patient Survey 2013-2014. Most people were in paid work $(57.1 \%$ of weighted 
Table 3 Characteristics of respondents to the General Practice Patient Survey 2013-2014

\begin{tabular}{|c|c|}
\hline Characteristic & $\begin{array}{l}\text { Number (unweighted; } \\
\text { weighted percentages) } \\
\text { of respondents }\end{array}$ \\
\hline \multicolumn{2}{|l|}{ Age (years) } \\
\hline $18-24$ & $34815(3.9 ; 9.7)$ \\
\hline $25-34$ & 80767 (9.1; 17.1) \\
\hline $35-44$ & $111298(12.5 ; 17.3)$ \\
\hline $45-54$ & $153641(17.3 ; 18.6)$ \\
\hline $55-64$ & $177966(20.0 ; 14.8)$ \\
\hline $65-74$ & $183908(20.7 ; 12.3)$ \\
\hline $75-84$ & $111332(12.5 ; 7.3)$ \\
\hline$\geq 85$ & $35492(4.0 ; 2.9)$ \\
\hline Total & 889219 \\
\hline \multicolumn{2}{|l|}{ Gender } \\
\hline Male & $385485(43.3 ; 49.0)$ \\
\hline Female & $503834(56.7 ; 51.0)$ \\
\hline Total & 889319 \\
\hline \multicolumn{2}{|l|}{ Ethnicity } \\
\hline White & 777904 (87.8; 87.1) \\
\hline Mixed & $6729(0.8 ; 1.0)$ \\
\hline Asian & $51629(5.8 ; 6.3)$ \\
\hline Black & $23581(2.7 ; 2.6)$ \\
\hline Other & $26215(3.0 ; 3.1)$ \\
\hline Total & 886058 \\
\hline \multicolumn{2}{|c|}{ Socio-economic status* } \\
\hline 1 (most deprived) & $186046(20.6 ; 20.6)$ \\
\hline 2 & 179379 (19.9; 20.0) \\
\hline 3 & $185234(20.5 ; 20.0)$ \\
\hline 4 & $181712(20.1 ; 19.7)$ \\
\hline 5 (least deprived) & 170498 (18.9; 19.8) \\
\hline Total & 902869 \\
\hline \multicolumn{2}{|c|}{ Can take time off work to see general practitioner } \\
\hline Not working $\dagger$ & $460614(54.0 ; 42.9)$ \\
\hline Yes & $269493(31.6 ; 38.4)$ \\
\hline No & $122589(14.4 ; 18.7)$ \\
\hline Total & 852696 \\
\hline \multicolumn{2}{|c|}{ Confident in managing health } \\
\hline Very & $365679(42.1 ; 42.8)$ \\
\hline Fairly & $436179(50.2 ; 49.7)$ \\
\hline Not very & $54953(6.3 ; 6.2)$ \\
\hline Not at all & $11818(1.4 ; 1.3)$ \\
\hline Total & 868629 \\
\hline
\end{tabular}

903357 survey respondents from 8005 general practices; data presented where available for each variable.

Weighted percentages account for survey design and non-response.

*Fifths of the national Index of Multiple Deprivation rank for lower layer super output areas of residence.

†Full-time education, unemployed, sick or disabled, retired, looking after home, other.

responses) with a minority unable to take time off work to see a GP (18.7\%). Table 4 shows that most respondents were very satisfied $(37.2 \%)$ or fairly satisfied $(42.7 \%)$ with the opening hours of their general
Table 4 Satisfaction with opening hours, experience of making an appointment and overall experience in the General Practice Patient Survey 2013-2014

\begin{tabular}{|c|c|}
\hline Question & $\begin{array}{l}\text { Number (unweighted; } \\
\text { weighted percentages) } \\
\text { of respondents }\end{array}$ \\
\hline \multicolumn{2}{|c|}{ 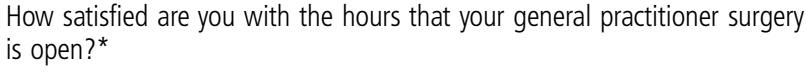 } \\
\hline Very dissatisfied & $21305(2.5 ; 3.1)$ \\
\hline Fairly dissatisfied & $48015(5.6 ; 6.8)$ \\
\hline Neither satisfied nor dissatisfied & $77306(9.0 ; 10.2)$ \\
\hline Fairly satisfied & $352262(41.1 ; 42.7)$ \\
\hline Very satisfied & $358987(41.8 ; 37.2)$ \\
\hline Total & 857875 \\
\hline \multicolumn{2}{|c|}{$\begin{array}{l}\text { Overall, how would you describe your experience of making an } \\
\text { appointment? }\end{array}$} \\
\hline Very poor & $26881(3.1 ; 4.1)$ \\
\hline Fairly poor & $50875(5.9 ; 7.4)$ \\
\hline Neither good nor poor & $99458(11.6 ; 13.9)$ \\
\hline Fairly good & $334833(39.0 ; 40.9)$ \\
\hline Very good & $346279(40.3 ; 33.8)$ \\
\hline Total & 858326 \\
\hline \multicolumn{2}{|c|}{$\begin{array}{l}\text { Overall, how would you describe your experience of your general } \\
\text { practitioner surgery? }\end{array}$} \\
\hline Very poor & $8146(0.9 ; 1.2)$ \\
\hline Fairly poor & $25043(2.8 ; 3.6)$ \\
\hline Neither good nor poor & $69618(7.9 ; 9.5)$ \\
\hline Fairly good & $342015(38.7 ; 42.6)$ \\
\hline Very good & $437868(49.6 ; 43.1)$ \\
\hline Total & 882690 \\
\hline
\end{tabular}

903357 survey respondents from 8005 general practices; data presented where available for each variable.

Weighted percentages account for survey design and non-response.

*Responses of 'I'm not sure when my GP surgery is open' were excluded $(n=25271)$.

practices. Results were similar for experience of making an appointment and the overall experience. Table 5 indicates that working people, particularly if they were unable to take time off work to see a GP, reported worse experiences across measures. Mean values of satisfaction with opening hours, experience of making an appointment and overall experience at the practice level were 78.5 (SD 6.3), 76.8 (9.4) and 83.1 (6.5), respectively.

Most of the included general practices participated in the extended hours access scheme in 2013-2014 $(73.9 \% ; 5492 / 7428)$. The mean payment to participating practices was $£ 10454$ (IQR $£ 5863-16772$ ). Participation rates and other characteristics of General Medical Services practices were comparable to those of Personal Medical Services practices (see online supplementary appendix 1). Figure 1 shows how mean values of the patient experience measures did not differ much by scheme participation. Table 6 presents estimates of adjusted mean differences, from random-effects regression, propensity score matching and instrumental variable analysis. 
Table 5 Mean satisfaction with opening hours, experience of making an appointment and overall experience in the General Practice Patient Survey 2013-2014, by ability to take time off work to see a general practitioner (GP)

\begin{tabular}{|c|c|c|c|}
\hline & $\begin{array}{l}\text { Satisfaction } \\
\text { with opening } \\
\text { hours }\end{array}$ & $\begin{array}{l}\text { Experience of } \\
\text { making an } \\
\text { appointment }\end{array}$ & $\begin{array}{l}\text { Overall } \\
\text { experience }\end{array}$ \\
\hline Overall & 78.4 & 76.8 & 83.2 \\
\hline \multicolumn{4}{|c|}{ Can take time off work to see a GP: } \\
\hline Not working ${ }^{*}$ & 82.6 & 80.3 & 86.2 \\
\hline Yes & 77.1 & 76.3 & 82.4 \\
\hline No & 65.3 & 65.0 & 74.2 \\
\hline
\end{tabular}

Mean values of outcome measures are on a 0-100 scale.

Table based on 852696 survey responses with non-missing data for row variables; data presented where available for outcome measures ( $n \geq 811589$ responses).

*Full-time education, unemployed, sick or disabled, retired, looking after home, other.

\section{Random-effects regression}

In the multilevel random-effects regression models, respondents registered to general practices participating in the scheme reported greater satisfaction with opening hours on average (mean difference 1.25, $95 \%$ CI 0.96 to 1.55$)$. The standardised mean difference of 0.28 indicates a small association with satisfaction. The scheme was estimated to have minimal associations with experience of making an appointment $(0.48,0.07$ to 0.90$)$ and overall experience $(0.32,0.04$ to 0.60$)$; the mean differences correspond to $0.07 \mathrm{SDs}$ in these measures of patient experience at the practice level.

The association of scheme participation with satisfaction with opening hours differed according to respondent ability to take time off work to see a GP ( $p<0.001$ for joint test of interactions). Table 7 shows a greater association for those unable to take time off (standardised mean difference 0.47) compared with respondents who were not in paid work $(0.20)$.

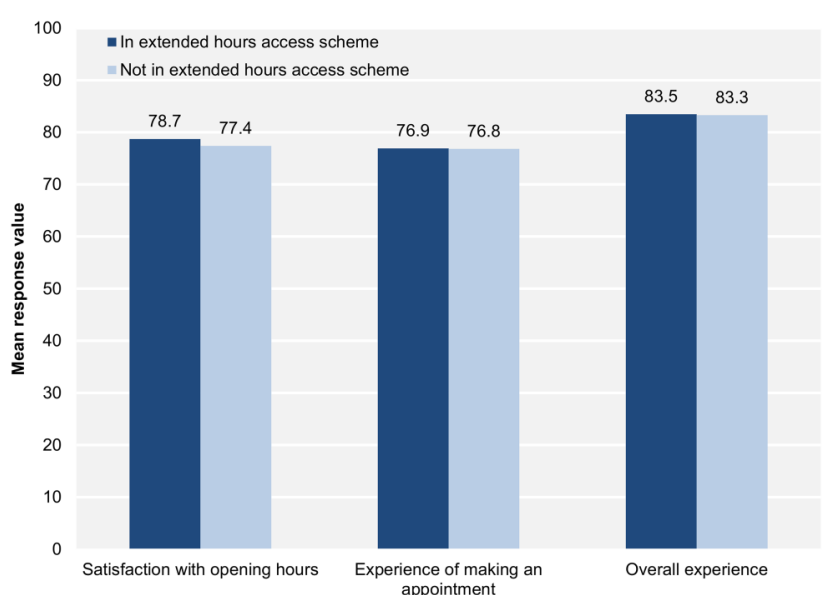

Figure 1 Mean satisfaction with opening hours, experience of making an appointment and overall experience by scheme participation.
There was no evidence of this effect modification for experience of making an appointment or overall experience $(\mathrm{p}=0.315$ and 0.788$)$. Figure 2 presents how the association for satisfaction with opening hours varied by region of England $(p<0.001)$. The largest association was seen for the East of England (mean difference $3.58,2.66$ to 4.49 ), while there was no evidence of an association in London $(-0.27$, -1.12 to $0.58 ; \mathrm{p}=0.531$ ). Mean differences typically remained minimal across regions for the other two experience measures (see online supplementary appendix 2).

Respondents who were unable to take time off work to see a GP or were not at all confident in managing their health reported substantially worse patient experiences (mean differences relative to those not working or those very confident in managing their health $\leq-7.96$; see online supplementary appendix 3 ). For example, mean satisfaction with opening hours for respondents who could not take time off work to see a GP was 14.62 (14.40 to 14.83 ) lower than for respondents who were not working. Patients who could take time off to see a GP responded more similarly to those not working across measures (eg, satisfaction with opening hours $-3.68,-3.82$ to -3.53 ).

\section{Propensity score matching}

General practices were more likely to participate in the extended hours access scheme if they had larger registered populations (OR for an SD increase 1.26, 1.18 to 1.35 ) or performed better in the Quality and Outcomes Framework (1.22, 1.15 to 1.28; see online supplementary appendix 4). Scheme participation was highest in the northeast of England (relative to East Midlands, 5.51, 3.85 to 7.90). Before matching, the largest standardised mean difference in a variable between the two participation groups was $18.5 \%$ (percentage of respondents in the north east of England); most variables were highly balanced (average standardised mean difference $4.5 \%$ ).

Using propensity score matching, participation in the extended hours access scheme was associated with a 1.35 (1.00 to 1.70) increase in satisfaction with opening hours (table 6). This estimate and those for the two other experience measures were similar to those from the random-effects regression models, thus supporting the specification of these regression models. Propensity score matching, in general, reduced the standardised mean differences in characteristics of the two participation groups; the average difference reduced to $0.5 \%$, indicating good matching quality (see online supplementary appendix 5). A suitable match could not be found for a very small number of respondents $(0.09 \%)$.

\section{Instrumental variable analysis}

The percentage of practices that participated in the scheme varied from $34.9 \%$ to $96.0 \%$ across categories 
Table 6 Adjusted associations between participation in the extended hours access scheme and patient experience, using multilevel random-effects regression models, propensity score matching and instrumental variable analysis

\begin{tabular}{|c|c|c|c|}
\hline & Satisfaction with opening hours & Experience of making an appointment & Overall experience \\
\hline Number of responses & 731700 & 725885 & 753020 \\
\hline Number of general practices & 7399 & 7399 & 7399 \\
\hline Between-practice SD* & 4.5 & 7.0 & 4.3 \\
\hline \multicolumn{4}{|l|}{ Random-effects regression models } \\
\hline Mean difference $(95 \% \mathrm{Cl})$ & $1.25(0.96$ to 1.55$)$ & $0.48(0.07$ to 0.90$)$ & $0.32(0.04$ to 0.60$)$ \\
\hline p Value & $<0.001$ & 0.022 & 0.026 \\
\hline Standardised mean difference & 0.28 & 0.07 & 0.07 \\
\hline \multicolumn{4}{|l|}{ Propensity score matching } \\
\hline Mean difference $(95 \% \mathrm{Cl})$ & $1.35(1.00$ to 1.70$)$ & $0.51(-0.03$ to 1.04$)$ & 0.39 (0.03 to 0.74$)$ \\
\hline $\mathrm{p}$ Value & $<0.001$ & 0.063 & 0.032 \\
\hline Standardised mean difference & 0.30 & 0.07 & 0.09 \\
\hline \multicolumn{4}{|l|}{ Instrumental variable analysis } \\
\hline Mean difference $(95 \% \mathrm{Cl})$ & $1.36(0.71$ to 2.00$)$ & $1.79(0.84$ to 2.75$)$ & $1.13(0.50$ to 1.76$)$ \\
\hline $\mathrm{p}$ Value & $<0.001$ & $<0.001$ & $<0.001$ \\
\hline Standardised mean difference & 0.30 & 0.25 & 0.26 \\
\hline
\end{tabular}

Numbers of responses and general practices correspond to respondents with no missing data for relevant outcome models.

Mean differences are relative to the means for general practices not participating in the scheme.

All models adjusted for/balanced: respondent age, gender, ethnicity, socio-economic status, ability to take time off work to see a GP, confidence in managing health; and general practice registered population size, number of full-time-equivalent GPs per 10000 patients, socio-economic status of registered population, Quality and Outcomes Framework achievement, urban/rural location and region of England.

${ }^{*}$ SD of practice-level random effects adjusted for patient characteristics only. Standardised mean differences equal mean differences divided by this SD.

Table 7 Associations of the extended hours access scheme with patient experience by ability to take time off work to see a general practitioner (GP), estimated using multilevel random-effects regression models

\begin{tabular}{|c|c|c|c|}
\hline & Satisfaction with opening hours & Experience of making an appointment & Overall experience \\
\hline \multicolumn{4}{|l|}{ Cannot take time off } \\
\hline Mean difference $(95 \% \mathrm{Cl})$ & 2.08 (1.53 to 2.63$)$ & $0.65(0.04$ to 1.26$)$ & $0.27(-0.18$ to 0.71$)$ \\
\hline p Value & $<0.001$ & 0.035 & 0.237 \\
\hline Standardised mean difference & 0.47 & 0.09 & 0.06 \\
\hline \multicolumn{4}{|l|}{ Can take time off } \\
\hline Mean difference $(95 \% \mathrm{Cl})$ & $1.52(1.16$ to 1.89$)$ & $0.57(0.10$ to 1.03$)$ & $0.37(0.04$ to 0.69$)$ \\
\hline p Value & $<0.001$ & 0.017 & 0.028 \\
\hline Standardised mean difference & 0.34 & 0.08 & 0.09 \\
\hline \multicolumn{4}{|l|}{ Not working* } \\
\hline Mean difference $(95 \% \mathrm{Cl})$ & $0.87(0.60$ to 1.15$)$ & $0.39(-0.01$ to 0.79$)$ & $0.30(0.03$ to 0.57$)$ \\
\hline$p$ Value & $<0.001$ & 0.057 & 0.028 \\
\hline Standardised mean difference & 0.20 & 0.06 & 0.07 \\
\hline
\end{tabular}

Categories based on responses to 'If you need to see a GP at your GP surgery during your typical working hours, can you take time away from your work to do this?'.

Model specification is the same as for random effects regression model in table 6 with interaction terms added between participation in the extended hours access scheme and ability to take time off work to see a GP.

$p$ Values for joint tests of interaction terms were $<0.001$ (opening hours), 0.315 (appointment) and 0.788 (overall).

*Full-time education, unemployed, sick or disabled, retired, looking after home, other.

of the instrumental variable (fifths of the percentage of practices participating in the scheme in each CCG). This variable explained $18.5 \%$ of variation in the probability that a respondent was registered to a participating practice (partial $\mathrm{R}^{2}=0.185 ; \mathrm{F}$ statistic $\geq 1702$ ). Other characteristics of general practices were generally similar across categories of the instrumental variable (see online supplementary appendix 6).
In the instrumental variable analysis, the estimated effect of scheme participation on mean satisfaction with opening hours was 1.36 (0.71 to 2.00) with a corresponding standardised mean difference of 0.30 , indicating a small effect on satisfaction (table 6). The mean differences for experience of making an appointment $(1.79,0.84$ to 2.75$)$ and overall experience $(1.13,0.50$ to 1.76$)$ were larger than as 


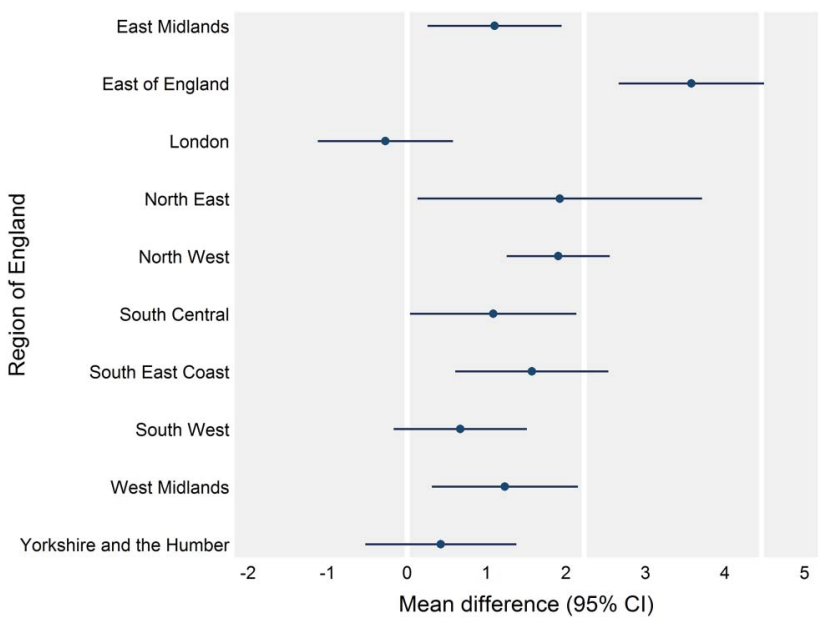

Figure 2 Associations of the extended hours access scheme with satisfaction with opening hours by region of England estimated using multilevel random effects regression models. Plotted estimates are adjusted mean differences and bars represent 95\% Cls. Reference lines are at 0, 0.5 (2.23) and 1 (4.46) SDs in satisfaction with opening hours at the practice level (see table 6).

estimated in the regression models and using propensity score matching, but effect sizes remained small (standardised mean differences 0.25 and 0.26 ).

\section{DISCUSSION}

In the General Practice Patient Survey 2013-2014, most respondents were satisfied with the opening hours of their general practices and had good experiences of making an appointment and of their practices overall. Most general practices participated in the extended hours access scheme. Random-effects regression models, propensity score matching and instrumental variable analysis all estimated the associations between scheme participation and patient experience measures to be positive but small. The association with satisfaction with opening hours was greatest for employed respondents who were unable to take time off work to see a GP, but this group still had substantially worse experiences across all measures. Results were generally consistent across regions of England.

\section{Strengths and limitations}

We suggest four strengths of the study. First, the study addresses two of the most prominent topics in current health policy in England-extended opening hours and patient experience of general practice. Second, we evaluated their relation using national data sets that include almost all general practices, such that the results are highly relevant to central government policy. The General Practice Patient Survey itself is monitored by government to assess NHS performance $^{20}$ and by practices to set opening hours under the extended hours access scheme.
Third, extended opening hours policies remain largely unevaluated. This paper is the first national analysis of such a policy and the first to use general practice payment data in this context. Fourth, using the multilevel structure of available data, we adjusted results for observed differences between patients and general practices and also tried to adjust for unobserved differences in the instrumental variable analysis. We thus tested the results' sensitivity to model assumptions and found consistent results across models.

A limitation was that the payment data do not indicate exactly when practices were extending their opening hours during the week. To our knowledge, valid national data on the exact opening times of practices do not exist; data reported by practices on an NHS information website are inaccurate. ${ }^{9}$ A telephone survey of a nationally representative $4 \%$ sample of practices suggests that around half of extended hours with GP face-to-face consultations are after 18:30 on weekdays (1.4 of 2.6 hours each week; 0.9 hours at weekends; 0.3 hours before 08:00). ${ }^{9}$ Other health professionals are also eligible to provide consultations under the scheme.

Cross-sectional studies are often limited by residual confounding. In this study, observed characteristics of patients and general practices were very similar between scheme participants and non-participants. Given this fact and the high rate of scheme participation, we do not expect potential sources of residual confounding to have important effects on the results. This includes possible non-response bias in the General Practice Patient Survey; response rates were similar between participation groups $(36.9 \%$ and $37.2 \%)$. Instrumental variable analysis, which attempts to explicitly address unmeasured confounding, produced similar results to other approaches.

Several explanations for the results that do not relate solely to the effect of scheme participation cannot be ruled out using a cross-sectional design. The scheme's introduction in 2008 could have improved patient experience in the short term, with extended opening hours increasingly part of normal expectations over time such that the effect has since reduced. Experiences in participating practices before they joined the scheme may also have been worse than the current experiences in non-participating practices. These alternative explanations, if true, would mean that the results presented underestimate the effect of the extended hours access scheme. A longitudinal study design was not feasible given the novelty of the extended hours access scheme data.

The analysis was limited to three experience measures that we thought were the most relevant to current policy. Associations with other experience measures may differ, however. In a supplementary analysis (requested in the journal review process), we estimated a multilevel regression model for an 
additional outcome measure relating to appointment convenience. This measure had five levels: no appointment, not at all convenient, not very convenient, fairly convenient and very convenient (interval scale from 0 to 100). The adjusted association with scheme participation was 0.55 (95\% CI 0.21 to 0.90 ), again indicating a minimal difference.

\section{Relation to existing literature}

Most respondents to the General Practice Patient Survey 2013-2014 found current opening times convenient $\left(79.9 \%\right.$ of weighted sample). ${ }^{47}$ The percentage reporting both that they were inconvenient and additional opening times on Saturdays would be helpful was $14.9 \%$, while it was $7.4 \%$ for Sundays; ${ }^{47}$ this does not necessarily mean that only a minority of patients would benefit from extending opening hours, however. Patients who cannot take time off work to see a GP are particularly less likely to find current opening times convenient, ${ }^{48}$ yet most of these respondents still do so (55.8\%). ${ }^{49}$ Those who can take time off work to see a GP are also less likely to find current times convenient (77.7\%) than people not in paid work (91.4\%). ${ }^{49}$ Many measures of patient experience in the General Practice Patient Survey have worsened year-on-year since 2011-2012. ${ }^{47} 50$ In international patient surveys, the timeliness of primary care in England still ranks highly. ${ }^{51}$

Patients who cannot take time off work to see a GP have long reported worse experiences of their general practices in national surveys. In 2007-2008, these patients reported being less able to get an appointment and to see a particular GP, as well as worse satisfaction with opening hours. ${ }^{31}$ Our results suggest that the extended hours access scheme might reduce some of these differentials but is unlikely to resolve them entirely. Respondents registered to practices with larger populations or located in certain regions, particularly London, also gave substantially more negative responses in 2007-2008. ${ }^{31}$ These findings are again consistent with our results. Other patient characteristics, such as younger age, also demonstrate consistent negative associations across experience measures. $^{23} 3141$

Overall experience was more strongly associated with the quality of doctor communication than the timing of appointments (within or more than two weekdays ahead) in the General Practice Patient Survey 2009-2010. ${ }^{52}$ Discrete choice experiments suggest that patients often give less weight to timings of appointments than other characteristics such as seeing a particular doctor. ${ }^{53-56}$ This may help explain why participation in the extended hours access scheme had a limited association with overall experience in our study. A previous analysis aimed to determine the effect of the introduction of the extended hours access scheme in 2008 in 13 of 152 areas of
England, but its validity is compromised by the unreliable data sources used (such as internet searches). ${ }^{57}$

The UK health secretary has stated that 'the role and purpose of seven day primary care is about much more than convenience-it is about making sure precious hospital capacity is kept clear for those who really need it'. ${ }^{2}$ Several national studies of the General Practice Patient Survey linked to hospital data suggest that general practices with greater access (relating here to the ability to get an appointment) have lower adjusted rates of both emergency department visits and emergency hospital admissions. ${ }^{58-68}$ However, the extent to which residual confounding explains these results is unknown; more robust longitudinal analyses are needed. ${ }^{47}$ There is likely to be much variability in the extent extended opening hours schemes improve access and for whom.

Programmes to extend opening hours in Manchester had a limited effect on use of emergency departments and patient experience, with results changing across model specifications and by local area. ${ }^{69}$ In London, four general practices that began opening 7 days a week reduced use of emergency departments relative to a local control group. ${ }^{70}$ The national evaluation of the first wave of the prime minister's GP access fund did not use methods that were adequate to determine its true effect on patient experience or use of hospital services. ${ }^{71}$ It did, however, identify little demand for appointments on Sundays in most pilots with some no longer opening on these days. ${ }^{71}$ National research funders should commission relevant academic evaluations.

\section{Policy implications}

Our results suggest that the extended hours access scheme has a limited association with patient experience. Assuming that this association represents the true effect of the scheme, possible explanations include that it is difficult to improve experiences beyond existing levels (diminishing marginal returns) and that some participating practices are redistributing appointments rather than offering more of them (contrary to scheme requirements). Alternatively, patients who use extra appointments may often not reflect this in their reported experiences despite the benefits gained; critical respondents, for example, may remain negative for reasons besides service provision. Many patients may simply be unaware of their practices' opening times, preventing extended hours from translating into improved satisfaction. The extra appointments may also be used by patients whom the intervention is not targeted at, such as those not in full-time work, who could otherwise get an appointment for another time. Our results do suggest that patients who are unable to take time off work to see a GP could benefit more from extended opening hours, however, which supports the mechanism expected to 
link extended hours to improved satisfaction in the General Practice Patient Survey.

The modest associations reported could instead be due to the limited size of the intervention-the minimum requirement of $30 \mathrm{~min}$ of additional appointments per 1000 registered patients each week is not a large change to opening hours for an average practice (equivalent to 3 hours and $45 \mathrm{~min}$ ). It may represent an even smaller change to the number of additional consultations provided, and these consultations may not be with patients' preferred health professionals. Since additional appointments can be provided concurrently (for at least $30 \mathrm{~min}$ ) to meet the minimum requirement, actual opening times may also not change that much. Revisions to the scheme may improve its benefit.

The results are also relevant to the prime minister's GP access fund (table 1a). In the first 20 pilot areas of the GP access fund, medium-sized pilots provided around $41 \mathrm{~min}$ of extended hours per 1000 registered patients each week. ${ }^{71}$ This is comparable to the minimum amount required by the extended hours access scheme alone, such that the effect on patient experience may be similarly limited. Moreover, the additional appointments can be provided collectively between practices working in groups in the pilot areas, in contrast to each practice individually extending opening hours under the extended hours access scheme 2013-2014. Therefore, patients may have to attend practices other than their own in pilot areas. These facts question the expected impact of extended opening hours on patient experience in the GP access fund pilots. Other interventions trialled in these pilots may contribute to any effects though, and other rationales besides improving patient experience exist. ${ }^{71}$

The national evaluation of the GP access fund pilot areas reported that $75 \%$ of appointments outside core times were used. It therefore cautiously suggested that around 30 min of extended hours per 1000 population per week would be optimal. ${ }^{71}$ This is the minimum set in the extended hours access scheme, which suggests that this scheme may be sufficient alone to extend hours suitably. It remains to be seen whether utilisation increases with time, however, and what the results from the second wave of pilot areas are.

Government plans for access to general practice appear unlikely to change soon. When once asked about the aim of 7-day working, the UK health secretary replied, 'Increasing convenience for the general public in terms of being able to make routine evening and weekend appointments is a manifesto commitment that this government made, so we have to honour that'. ${ }^{1}$ Improving patient experience has been given as one of three key objectives for these changes. ${ }^{71}$ In conclusion, this study questions whether large improvements in patient experience will be achieved through existing changes to opening hours alone.
Contributors TEC conceived and designed the work, acquired and analysed the data and wrote the article. MH and AM contributed to revision of the analysis plan, interpretation of the data and revision of the article. All authors gave final approval of the version to be published. TEC is guarantor.

Funding This report is independent research supported by the National Institute for Health Research (NIHR) (Doctoral Research Fellowship, Thomas Cowling, DRF-2013-06-142). The views expressed in this publication are those of the authors and not necessarily those of the NHS, the NIHR or the Department of Health.

Competing interests None declared.

Ethics approval Approval was obtained from NHS England to use General Practice Patient Survey data for research purposes.

Provenance and peer review Not commissioned; externally peer reviewed.

Open Access This is an Open Access article distributed in accordance with the terms of the Creative Commons Attribution (CC BY 4.0) license, which permits others to distribute, remix, adapt and build upon this work, for commercial use, provided the original work is properly cited. See: http://creativecommons.org/licenses/by/4.0/

\section{REFERENCES}

1 Health Committee. Oral evidence: Work of the Secretary of State for Health. 2015. http://data.parliament.uk/ writtenevidence/committeeevidence.svc/evidencedocument/ health-committee/work-of-the-secretary-of-state-for-health/oral/ 21669.pdf

2 Hunt J, Department of Health. New deal for general practice. 2015. https://www.gov.uk/government/speeches/new-dealfor-general-practice

3 Iacobucci G. Cameron reiterates promise of seven day access to GPs. BMJ 2014;349;g5960.

4 Prime Minister's Office, 10 Downing Street, Department of Health, et al. PM on plans for a seven-day NHS. 2015. https:// www.gov.uk/government/speeches/pm-on-plans-for-aseven-day-nhs

5 Department of Health. Millions to benefit from improved GP care. 2014. https://www.gov.uk/government/news/ millions-to-benefit-from-improved-gp-care

6 Prime Minister's Office, 10 Downing Street, Department of Health, et al. Prime Minister pledges to deliver 7-day GP services by 2020. 2015. https://www.gov.uk/government/news/ prime-minister-pledges-to-deliver-7-day-gp-services-by-2020

7 Department of Health. Seven day, $8 \mathrm{am}-8 \mathrm{pm}$, GP access for hard working people. 2013. https://www.gov.uk/government/ news/seven-day-8am-8 pm-gp-access-for-hard-working-people? utm_source $=$ rss\&utm_medium $=$ rss\&utm_campaign $=$ press-release-seven-day- $8 \mathrm{am}-8 \mathrm{pm}$-gp-access-forhard-working-people

8 Department of Health, NHS England, Health Education England. Health Committee primary care inquiry: written evidence submitted by the Department of Health, NHS England and Health Education England (PRI0200). 2015. http://data.parliament.uk/writtenevidence/committeeevidence. svc/evidencedocument/health-committee/primary-care/written/ 21020.pdf

9 Richards EC, Cowling TE, Gunning EJ, et al. Online data on opening hours of general practices in England: a comparison with telephone survey data. Br J Gen Pract 2015;65:e806-12.

10 Royal College of General Practitioners. Health Committee primary care inquiry: written evidence submitted by RCGP (PRI0174). 2015. http://data.parliament.uk/writtenevidence/ 
committeeevidence.svc/evidencedocument/health-committee/ primary-care/written/20769.pdf

11 Australian Department of Health. After hours primary health care. 2015. http://www.health.gov.au/internet/main/publishing. nsf/Content/primary-ahphc

12 European Observatory on Health Systems and Policies. Health Systems in Transition (HiT) profile of Italy. 2015. http://www. hspm.org/countries/italy25062012/livinghit.aspx?Section= 6.3\%20Primary $\% 20 / \% 20$ ambulatory $\% 20$ care $\&$ Type $=$ Section

13 Aysola J, Rhodes KV, Polsky D. Patient-centered medical homes and access to services for new primary care patients. Med Care 2015;53:857-62.

14 Department of Health. The Primary Medical Services (Directed Enhanced Services) Directions 2015. 2015. https:// www.gov.uk/government/uploads/system/uploads/ attachment_data/file/417192/pms-des-directions-2015.pdf

15 Department of Health. General Medical Services Statement of Financial Entitlements Directions 2013. 2013. https://www.gov. uk/government/uploads/system/uploads/attachment_data/file/ 233366/gen_med_servs_statement_financial_entitlements_ directions_2013_acc.pdf

16 Health and Social Care Information Centre. Number of Patients Registered at a GP Practice-October 2015. 2015. http://www.hscic.gov.uk/searchcatalogue? productid $=19077 \&$ topics $=2 \% 2$ frimary + care + services $\%$ $2 \mathrm{fGeneral}+$ practice $\% 2 \mathrm{fGP}+$ registered + population\&sort $=$ Relevance\&size $=10 \&$ page $=1 \#$ top

17 Health and Social Care Information Centre. NHS Payments to General Practice, England, 2014-15. 2015. http://www.hscic. gov.uk/searchcatalogue? productid $=18806 \&$ topics $=2 \%$ $2 \mathrm{fPrimary}+$ care + services $\% 2 \mathrm{fGeneral}+$ practice $\% 2 \mathrm{fGP}$ + registered + population\&sort $=$ Most + recent\&size $=10 \&$ page $=1 \#$ top

18 NHS Employers. Extended hours access directed enhanced service (DES) 2013/14. 2013. http://www.nhsemployers.org/ $\sim /$ media/Employers/Publications/2013_14_extended_hours_ DES_guidance.pdf

19 Ipsos MORI. GP Patient Survey. 2015. https://gp-patient.co.uk/

20 Department of Health. NHS Outcomes Framework 2015 to 2016. 2014. https://www.gov.uk/government/publications/ nhs-outcomes-framework-2015-to-2016

21 Ipsos MORI. GP patient survey-technical annex: 2013-14 annual report. 2014. http://gp-survey-production.s3. amazonaws.com/archive/2014/July/1301375001_Technical\% 20Annex\%202013-2014_FINAL\%20v1.pdf

22 Lyratzopoulos G, Elliott MN, Barbiere JM, et al. How can health care organizations be reliably compared?: lessons from a national survey of patient experience. Med Care 2011;49:724-33.

23 Lyratzopoulos G, Elliott M, Barbiere JM, et al. Understanding ethnic and other socio-demographic differences in patient experience of primary care: evidence from the English General Practice Patient Survey. BMJ Qual Saf 2012;21:21-9.

24 Warren FC, Abel G, Lyratzopoulos G, et al. Characteristics of service users and provider organisations associated with experience of out of hours general practitioner care in England: population based cross sectional postal questionnaire survey. BMJ 2015;350:h2040.

25 Roberts MJ, Campbell JL, Abel GA, et al. Understanding high and low patient experience scores in primary care: analysis of patients' survey data for general practices and individual doctors. BMJ 2014;349:g6034.
26 Health and Social Care Information Centre. NHS Payments to General Practice, England, 2013-14: Experimental Statistics. 2015. http://www.hscic.gov.uk/catalogue/PUB16847

27 Health and Social Care Information Centre. General and Personal Medical Services, England-2004-14, As at 30 September 2015. http://www.hscic.gov.uk/searchcatalogue? productid $=17387 \&$ topics $=2 \% 2 \mathrm{fWorkforce} \% 2 \mathrm{fStaff}+$ numbers $\% 2 \mathrm{fGeneral}+$ practice + staff $\&$ sort $=$ Relevance $\&$ size $=$ 10\&page $=1 \#$ top

28 Department of Health. Standard General Medical Services Contract. 2013. https://www.gov.uk/government/publications/ standard-general-medical-services-contract

29 NHS England. NHS England Standard Personal Medical Services Agreement 2015/16. 2015. https://www.england.nhs. uk/commissioning/wp-content/uploads/sites/12/2015/06/ pms2015-16.pdf

30 Coleman A, Checkland K, McDermott I, et al. The limits of market-based reforms in the NHS: the case of alternative providers in primary care. BMC Health Serv Res 2013;13 (Suppl 1):S3.

31 Kontopantelis E, Roland M, Reeves D. Patient experience of access to primary care: identification of predictors in a national patient survey. BMC Fam Pract 2010;11:61.

32 Office for National Statistics. Ethnic group. 2015. http://www. ons.gov.uk/ons/guide-method/measuring-equality/equality/ ethnic-nat-identity-religion/ethnic-group/index.html

33 McLennan D, Barnes H, Noble M, et al. The English Indices of Deprivation 2010. 2011. https://www.gov.uk/government/ uploads/system/uploads/attachment_data/file/6320/1870718.pdf

34 Health and Social Care Information Centre. General and Personal Medical Services, England-2003-13, As at 30 September 2014. http://www.hscic.gov.uk/searchcatalogue? productid $=14458 \&$ topics $=2 \% 2 \mathrm{fWorkforce} \% 2 \mathrm{fStaff}+$ numbers $\% 2 \mathrm{fGeneral}+$ practice + staff $\&$ sort $=$ Relevance $\&$ size $=10$ \&page $=1 \#$ top

35 Department for Communities and Local Government. English indices of deprivation 2010. 2011. https://www.gov.uk/ government/statistics/english-indices-of-deprivation-2010

36 Office for National Statistics. $2011 \mathrm{rural} / \mathrm{urban}$ classification. 2015. http://www.ons.gov.uk/ons/guide-method/geography/ products/area-classifications/2011-rural-urban/index.html

37 Health and Social Care Information Centre. Quality and Outcomes Framework (QOF)—2013-14, 2014. http://www. hscic.gov.uk/searchcatalogue? productid $=16273 \&$ topics $=1 \%$ 2 fPrimary + care + services $\% 2$ fQuality + Outcomes + Framework\&sort $=$ Title\&size $=100 \&$ page $=1 \#$ top

38 Llanwarne NR, Abel GA, Elliott MN, et al. Relationship between clinical quality and patient experience: analysis of data from the english quality and outcomes framework and the National GP Patient Survey. Ann Fam Med 2013;11:467-72.

39 Doran T, Fullwood C, Gravelle H, et al. Pay-for-performance programs in family practices in the United Kingdom. N Engl J Med 2006;355:375-84.

40 Dusheiko M, Doran T, Gravelle H, et al. Does higher quality of diabetes management in family practice reduce unplanned hospital admissions? Health Serv Res 2011;46:27-46.

41 Paddison CA, Saunders CL, Abel GA, et al. Why do patients with multimorbidity in England report worse experiences in primary care? Evidence from the general practice patient survey. BMJ Open 2015;5:e006172.

42 Blundell R, Dearden L, Sianesi B. Evaluating the effect of education on earnings: models, methods and results from the 
National Child Development Survey. J R Stat Soc 2005;168:473-512.

43 Leuven E, Sianesi B. PSMATCH2: Stata module to perform full Mahalanobis and propensity score matching, common support graphing, and covariate imbalance testing (version 4.0.11). 2014. http://ideas.repec.org/c/boc/bocode/s432001. html

44 Baiocchi M, Cheng J, Small DS. Instrumental variable methods for causal inference. Stat Med 2014;33:2297-340.

45 Davies NM, Smith GD, Windmeijer F, et al. Issues in the reporting and conduct of instrumental variable studies: a systematic review. Epidemiology 2013;24:363-9.

46 Naylor C, Curry N, Holder H, et al. Clinical commissioning groups: supporting improvement in general practice? 2013. http://www.kingsfund.org.uk/sites/files/kf/field/ field_publication_file/clinical-commissioning-groupsreport-ings-fund-nuffield-jul13.pdf

47 Cowling TE, Harris MJ, Majeed A. Evidence and rhetoric about access to UK primary care. BMJ 2015;350:h1513.

48 Ford JA, Jones AP, Wong G, et al. Weekend opening in primary care: analysis of the general practice patient survey. Br J Gen Pract 2015;65:e792-8.

49 Cowling TE, Gunning EJ. Access to general practice in England: political, theoretical and empirical considerations. Br J Gen Pract 2016; [In Press].

50 Ipsos MORI. GP Patient Survey-National summary report. 2015. http://gp-survey-production.s3.amazonaws.com/archive/ 2015/July/July\%202015\%20National\%20Summary\% 20Report.pdf

51 Davis K, Stremikis K, Squires D, et al. Mirror, mirror on the wall: how the performance of the U.S. health care system compares internationally. 2014. http://www. commonwealthfund.org/publications/fund-reports/2014/jun/ mirror-mirror

52 Paddison CA, Abel GA, Roland MO, et al. Drivers of overall satisfaction with primary care: evidence from the English General Practice Patient Survey. Health Expect 2015;18:1081-92.

53 Gerard K, Salisbury C, Street D, et al. Is fast access to general practice all that should matter? A discrete choice experiment of patients' preferences. J Health Serv Res Policy 2008;13(Suppl 2):3-10.

54 Cheraghi-Sohi S, Hole AR, Mead N, et al. What patients want from primary care consultations: a discrete choice experiment to identify patients' priorities. Ann Fam Med 2008;6:107-15.

55 Turner D, Tarrant C, Windridge K, et al. Do patients value continuity of care in general practice? An investigation using stated preference discrete choice experiments. J Health Serv Res Policy 2007;12:132-7.

56 Rubin G, Bate A, George A, et al. Preferences for access to the GP: a discrete choice experiment. Br J Gen Pract 2006;56:743-8.

57 Morgan CL, Beerstecher HJ. Satisfaction, demand, and opening hours in primary care: an observational study. $\mathrm{Br} J$ Gen Pract 2011;61:e498-507.
58 Cowling TE, Cecil EV, Soljak MA, et al. Access to primary care and visits to emergency departments in England: a cross-sectional, population-based study. PLoS ONE 2013;8: e66699.

59 Bottle A, Tsang C, Parsons C, et al. Association between patient and general practice characteristics and unplanned first-time admissions for cancer: observational study. $\mathrm{Br} \mathrm{J}$ Cancer 2012;107:1213-19.

60 Brettell R, Soljak M, Cecil E, et al. Reducing heart failure admission rates in England 2004-2011 are not related to changes in primary care quality: national observational study. Eur J Heart Fail 2013;15:1335-42.

61 Calderon-Larranaga A, Carney L, Soljak M, et al. Association of population and primary healthcare factors with hospital admission rates for chronic obstructive pulmonary disease in England: national cross-sectional study. Thorax 2011;66:191-6.

62 Calderón-Larrañaga A, Soljak M, Cecil E, et al. Does higher quality of primary healthcare reduce hospital admissions for diabetes complications? A national observational study. Diabet Med 2014;31:657-65.

63 Calderón-Larrañaga A, Soljak M, Cowling TE, et al. Association of primary care factors with hospital admissions for epilepsy in England, 2004-2010: National observational study. Seizure 2014;23:657-61.

64 Soljak M, Calderon-Larrañaga A, Sharma P, et al. Does higher quality primary health care reduce stroke admissions? A national cross-sectional study. Br J Gen Pract 2011;61:e801-7.

65 Scantlebury R, Rowlands G, Durbaba S, et al. Socioeconomic deprivation and accident and emergency attendances: cross-sectional analysis of general practices in England. $\mathrm{Br} \mathrm{J}$ Gen Pract 2015;65:e649-54.

66 Kasteridis P, Mason AR, Goddard MK, et al. The influence of primary care quality on hospital admissions for people with dementia in England: a regression analysis. PLOS ONE 2015;10:e0121506.

67 Cowling TE, Harris M, Watt $\mathrm{H}$, et al. Access to primary care and the route of emergency admission to hospital: retrospective analysis of national hospital administrative data. BMJ Qual Saf 2016;25:432-40.

68 Cowling TE, Harris MJ, Watt HC, et al. Access to general practice and visits to accident and emergency departments in England: cross-sectional analysis of a national patient survey. Br J Gen Pract 2014;64:e434-9.

69 NIHR CLAHRC Greater Manchester. NHS Greater Manchester Primary Care Demonstrator Evaluation. 2015. http://clahrc-gm.nihr.ac.uk/cms/wp-content/uploads/ PCDE-final-report-full-final.pdf

70 Dolton P, Pathania V. Averting an Accident: Can 7-Day GP Opening Save Accident \& Emergency? 2015. https:// editorialexpress.com/cgi-bin/conference/download.cgi? db_name $=$ RES2015\&paper_id $=867$

71 Mott MacDonald. Prime Minister's Challenge Fund: Improving Access to General Practice-First Evaluation Report. 2015. https://www.england.nhs.uk/wp-content/uploads/2015/ 10/pmcf-wv-one-eval-report.pdf 